\title{
Herpes Simplex Virus 1 DNA (Presence)
}

National Cancer Institute

\section{Source}

National Cancer Institute. Herpes Simplex Virus 1 DNA (Presence). NCI Thesaurus. Code C132855.

This assay detects the presence of nucleic acid sequences from the Herpes simplex virus 1 DNA in cerebrospinal fluid (CSF) using PCR and non-probe based detection methods, such as melt curve analysis. (LOINC) 